\title{
Métodos e técnicas de tRATAMENTO de ÁgUA
}

\section{LuIz Di BERNARdo E ÂNGELA Di BERNARDo DANTAS}

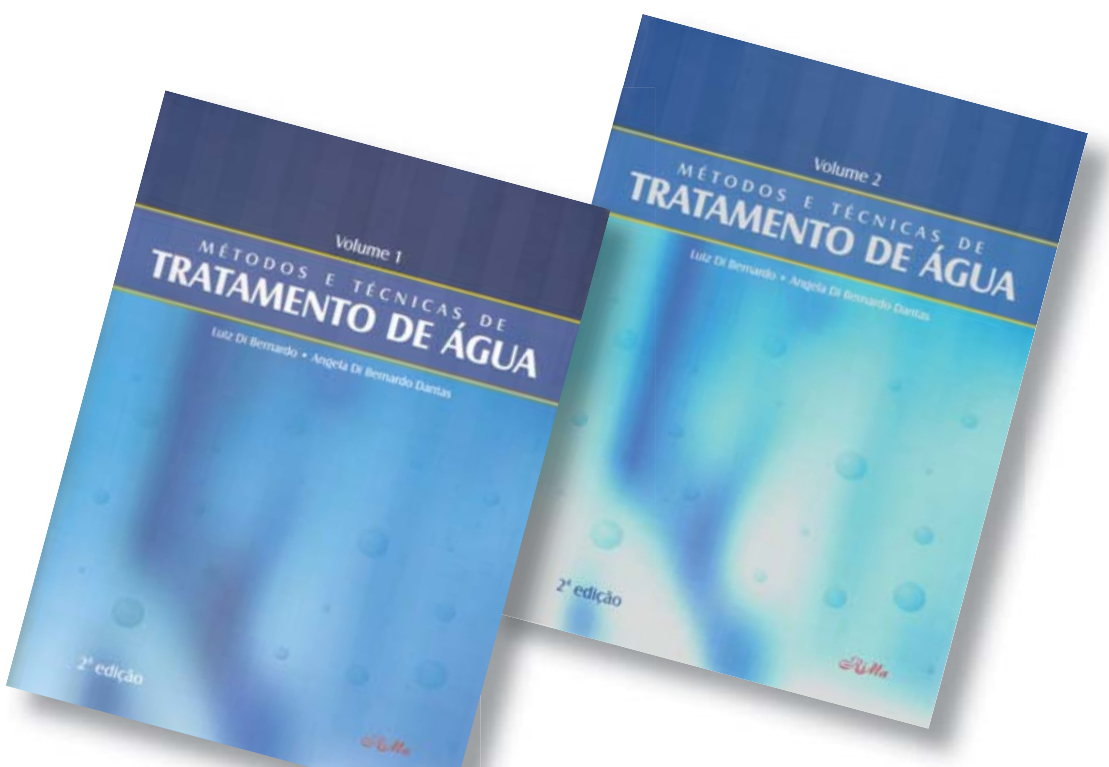

desejam elucidar dúvidas de projeto e para estudantes, especialmente de pósgraduação, que buscam aprofundar os conhecimentos sobre tratamento de água.

Por meio de diversos exemplos, o leitor pode perceber a importância da realização de investigação experimental para "conhecer a água" e, somente a partir desse conhecimento, propor a alternativa de tratamento mais adequada. Ou seja, tratar água exige um esforço intelectual muito além da simples repetição de procedimentos que deram certo em algum lugar, para alguma água.

O livro de autoria de Luiz Di Bernardo e Angela Di Bernardo Dantas é fartamente ilustrado com fotografias e desenhos e incorpora resultados de pesquisas muito recentes, algumas delas concluídas em 2005. O leitor que percorrer as 1565 páginas desta obra aprenderá sobre propriedades da água; casa de química; uso de traçadores na avaliação do comportamento hidrodinâmico das unidades de tratamento; coagulação e floculação; decantação convencional e de alta taxa; flotação por ar dissolvido; fundamentos da filtração e adsorção (capítulo 18); Automação de processos, operações e monitoramento (capítulo 19). Todos os 19 capítulos do livro refletem a preocupação dos autores em apresentar fundamentos teóricos e práticos relativos aos diversos temas, o que torna o livro uma fonte de consulta importante para engenheiros que rápida e da fluidificação; tecnologias de tratamento de água, incluindo o tratamento de ciclo completo, a filtração direta descendente, filtração direta ascendente, dupla filtração, a flotofiltração e filtração em múltiplas etapas; desinfecção e oxidação; resíduos gerados no tratamento; precipitação e adsorção; automação de processos.

Para completar a obra, que é a publicação sobre tratamento de água mais importante do país, faltou apenas um capítulo sobre "Estabilização química da água”. Esse livro reflete o conhecimento acumulado pelos autores em mais de 30 anos de intensa dedicação à "arte e à ciência" do tratamento de água, conhecimento transmitido de pai para filha, de professor para aluno, de orientador para mais de 80 orientados de mestrado e de doutorado que estão espalhados pelo país e pelo exterior retransmitindo e gerando conhecimentos.

Por muitas razões esta é uma obra que não deve faltar nas bibliotecas das nossas universidades, nas empresas de saneamento e nem na biblioteca particular de professores, engenheiros, químicos e estudantes de pós-graduação que desejam se especializar e conhecer em profundidade os métodos e técnicas de tratamento de água.

Comentários feitos por Valter Lúcio de Pádua Departamento de Engenharia Sanitária e Ambiental da Universidade Federal de Minas Gerais

\section{Coordenador da coluna Livrosa Prof. Gícero Onofre de Andrade Neto}

A sessão "Livros Técnicos", que a cada edição traz resumos comentados sobre livros de interesse na área, tem como principal objetivo permitir que o leitor, de forma rápida, se atualize e conheça o que há disponível no mercado editorial. As contribuiçōes deverão ser encaminhadas para: esa@abes-dn.org.br 